\title{
La realidad es un tigre. El mundo en la poesía de Isabel Fraire
}

\author{
Reality is a tiger. The World in Isabel Fraire's Poetry \\ LiLia SolóRZANo EsQUedA \\ ORCID: 0000-0001-5483-8288 \\ Universidad de Guanajuato, México \\ liliasolorzano@hotmail.com
}

\section{Resumen:}

Isabel Fraire es una poeta mexicana muy poco revisada en los estudios literarios. En una primera parte de este artículo se hace un seguimiento de algunos aspectos biográficos y puntos destacables de sus primeros textos que incluyen el poemario Sólo esta luæ: En un segundo momento se analiza el viraje de su producción poética a partir de Poemas en el regazo de la muerte mediante la simbología en la expresión de la poeta: "la realidad es un tigre", en alusión al sentido nietzscheano de lo terrible que puede llegar a ser la naturaleza humana y lo que la conciencia ha querido negar, su lado destructor. La propuesta es intentar acercarnos a lo que prefigura esa realidad amenazante y también vivificante en la poesía de Fraire.

\section{Palabras clave:}

Isabel Fraire, poesía mexicana, realidad terrible.

Abstract:

Isabel Fraire is a very unrevised Mexican poet in literary studies. The first part of this article tracks some biographical aspects and highlights of his early poetic work included in his book Sólo 
esta luz. In a second moment we analyze the turn of her poetic production from Poemas en el regazo de la muerte through the symbolism in the poet's expression: "reality is a tiger", alluding to the Nietzschean sense of how terrible human nature can become and what consciousness has wanted to deny: its destroying side. The proposal is to try to approach to what this menacing and also life-giving reality in Fraire's poetry foreshadows.

Keywords:

Isabel Fraire, Mexican Poetry, Terrible reality.

DOI: https://doi.org/10.36798/critlit.v0i23.383

Recibido: 01 de marzo de 2021

Aceptado: 18 de mayo de 2021

\section{Sobre la eclosión de la poeta}

En una entrevista, siendo ya mayor, Isabel Fraire cuenta con cierta pasión una historia que aduce es parte de su biografía: afirma que la raptaron, arrebatándola de sus padres siendo niña, en un pueblito de Estados Unidos. ${ }^{1}$ A raíz de este suceso, dice, creció hablando en

\footnotetext{
${ }^{1}$ No he podido verificar el dato porque hay muy poco escrito sobre la poeta regiomontana. Ella misma parece que negara toda referencia a su persona, por eso mismo resulta tan singular la especie de confidencia pública declarada en la serie de videos "Escritores y poetas mexicanos: Isabel Fraire". En el inicio de una novela autobiográfica que se ha recuperado ("Son chones"), Fraire refiere esa misma historia de rapto, salvo que atribuida a su madre. Su madre fue llamada Elizabeth Stiles Benson desde que fue literalmente robada a sus padres biológicos, miembros de una compañía teatral que pasaba por el pueblo, con el único fin de evitar el crecimiento de la pequeña en el seno de esa familia a la que se acusó de ser pecadora y soliviantada, por el mero hecho de ser francesa la madre y el padre irlandés, y de ir de acá para allá representando sketches. Debo añadir que en la dedicatoria del volumen Seis poetas de lengua inglesa, Fraire pone "A Anabel Stiles Benson (mi abuela, que me enseñó inglés cuando tenía yo tres años)" (sp). ¿A quién creer: a la memoria un poco juguetona y errática de la mujer mayor o a la
} 
otros idiomas, principalmente el inglés. En la misma conversación sostiene haber realizado, en su juventud, funciones de una especie de amanuense o secretaria. Su trabajo consistía en transcribir lo que algunos empleados o representantes de instituciones oficiales le dictaban y menciona que ese azar predispuso su inclinación a la escritura, porque "lo anotaba todo" (Fraire en Flores, "Escritores y poetas"). Una afirmación que se antoja un poco naive: que el trabajo por una necesidad de manutención le marcara su futura vocación u oficio de escritora. Ingenuo, tal vez, aunque una verdad muy extendida entre el gremio de escritores. En la obra completa de Fraire, que más bien es breve, se puede contar un apartado bastante interesante de textos periodísticos, entre reportajes, crónicas y entrevistas, reseñas y columnas de suplementos con inclinación hacia el ensayo creativo.

Isabel Fraire nació el 30 de julio de 1934, en Monterrey, Nuevo León. De 1960 a 1965 colaboró con la Revista Mexicana de Literatura. Entre 1977 y 1981 escribió la columna "Al margen" en el suplemento Sábado del Unomásuno. Durante la época que Tomás Segovia dirigió la Revista Mexicana de Literatura, 1959-1962, Isabel Fraire colaboró en ella. En 1963, cuando la estafeta pasó a manos de su amigo Juan García Ponce, Fraire era parte del equipo de redacción.

Había publicado en El corno emplumado, otra interesante revista cosmopolita de miras abolicionistas de fronteras, bilingüe, y que tenía como centros la Ciudad de México y Nueva York. Sus páginas acogieron la poesía estadounidense y la latinoamericana. Gracias a

voz de la autobiografía novelada? Esta última se detiene, dejando al lector en suspenso, justo cuando la protagonista cumple "la edad fatídica de los tres años", lo que abre un compás de ambigüedad nuevamente entre los dos relatos ya citados. Fraire nos ha dejado, con su seductora prosa, una serie de estampas y anécdotas que lo mismo componen un fresco socioeconómico de una época, que retratan las costumbres de familia de gente adinerada —o que desea serlo- y que compró aristocracia mediante los negocios y el matrimonio. Ahí también se puede leer un dato interesante: aprendió a leer con un libro regalo de su abuela, una edición "bellísima" — describe Fraire_ de Mamá la Oca, "así aprendí, no sólo inglés, sino el goce de las rimas y las palabras" (Fraire, "Son chones y asi son”). 
sus editores y colaboradores, el mundo hispanoparlante conoció al movimiento poético beat. Estuvo dirigida por su también amigo y poeta mexicano Sergio Mondragón y por Margaret Randall. Por cierto que junto a Mondragón, José Carlos Becerra, Gabriel Zaid y Francisco Cervantes apareció Fraire en una selección titulada "Cinco poetas mexicanos" (nótese la ausencia del adjetivo "jóvenes" que casi siempre acompaña a antologías de este tipo), en la revista Correspondencias, de otro poeta que también emergía en los sesenta y que también publicó en El corno emplumado, Homero Aridjis. En 1977, Thomas Hoeksema escribía sobre Fraire:

En el contexto de la poesía mexicana contemporánea hay una joven poeta que aunque sólo ha publicado un delgado volumen de poesía, ha desarrollado ya una madura voz poética. Isabel Fraire es casi desconocida fuera de un pequeño círculo de escritores mexicanos y traductores norteamericanos; sin embargo, es una de las poetas jóvenes más prometedoras. En 1969 publicó su primer y único libro [lo era aún en la fecha en que el crítico escribía estas líneas], Sólo esta luz (México, Era). El libro comprende poemas escritos durante un periodo de casi diez años, y fue finalmente publicado ante la insistencia de sus amigos Juan García Ponce y Tomás Segovia. (14)

Fraire ha dicho que la poesía es un puente, el mejor. ¿Un puente que une qué extremos? Pues varios, pero entre esos elementos se cuentan el lector y eso que se anota en la palabra escrita; entre el mundo referenciado por el poeta y el mundo imaginado por el lector; entre una lengua y otra, cuando se trata de traducciones; y entre pensamiento y poesía, también. Tal vez por ello a su primera antología editada por la Universidad Autónoma Metropolitana, en 1997, se le llamó Puente colgante.

En la nota introductoria que aparece en la colección que realizó de la poeta para Material de lectura de la Universidad Nacional Autónoma de México, García Ponce nos comparte lo que para él es una de sus estrategias poéticas más significativas: 
Isabel Fraire juega con las palabras, las acomoda como en un rompecabezas o como en un calidoscopio para recordar uno de sus objetos favoritos e insinuar un poco el carácter mágico y casual de ese juego en el que siempre interviene el azar para fijar las posibilidades de la belleza. La regla básica de ese juego, la regla a la que el poeta no puede dejar de someterse porque la obedece aún sin darse cuenta, es crear una serie de apariciones mediante las que el mundo se refleja en el poema y el poema en el mundo. Sueltas, haciéndose eco una a la otra, huyendo y reuniéndose, las palabras van fijando los precisos perfiles de una imagen que continuamente se desvanece y vuelve a mostrarse. (5-6)

Como conocía muy bien el inglés, su contacto con las poéticas de escritores estadunidenses e ingleses fue asiduo. Y tanto, que legó una importante traducción de Ezra Pound, T. S. Eliot, E. E. Cummings, Wallace Stevens, William Carlos Williams, W. H. Auden, recogida en el volumen Seis poetas de lengua inglesa (1976). Por lo menos se puede rastrear en la tesitura de sus imágenes, que es algo de lo muy remarcable en Fraire, el estilo y las sugerencias que Pound establece en su ya legendaria guía o poética propuesta en El arte de la poesía. Esas "sentencias" poundianas que hacen pensar en el arte poética horaciana: raro y paradójico: lo vanguardista se toca con lo más clásico. Ese volumen de Fraire responde a su "gusto personal" (Seis poetas 7 ), aunque cree que:

en cuanto al valor histórico, da la casualidad de que al menos cuatro de ellos: Eliot, Pound, Cummings y Williams, son piedras angulares de todo desarrollo posterior en la poesía de lengua inglesa, y que cuando menos tres de ellos: Eliot, Pound y Williams, han influido en la poesía latinoamericana. (Seis poetas 7)

En su poesía es destacable esta economía en la composición de imágenes: concisa y certera; por más que insista en que eso de las "influencias" le importa "un bledo" (Seis poetas 9), es evidente que "el aparato comunicante, verbal, musical, significativo, sugerente, 
que es el poema" (Seis poetas 9) lleva un fondo muy bien pensado, decantado, en el que se pueden rastrear a la lejanía ciertas formas y matices de esos poetas. Como cuando alcanzamos a distinguir algunos ecos o remembranzas muy sutiles: un aroma, una nota, un color. La presencia de la familiaridad. Fraire fue una excelente alumna de estos poetas anglófonos, en su poesía va directo al tema o lo va cercando mediante imágenes donde lo primero que se distingue es la erradicación de la retórica abundante. Nada de pirotecnia verbal, nada de artilugios que distraigan. Concentración y dominio del espacio. La hoja en blanco se rinde ante el poderoso magnetismo de su palabra:

De pronto rasga el día una herida luminosa como en el sexo virgen entra a saco la gloria lo nunca visto ni sentido nos rodea cómo resistir el oleaje de luz que nos envuelve hay una herida palpitante que todo lo contiene no hay diferencia ya entre beber y ahogarse (Kaleidoscopio 108)

El contraste de las imágenes oximorónicas de estos versos de su primer libro, "herida luminosa" o que en la violencia de entrar a saco a un sitio virginal quepa la gloria, y definir con ello una luz casi total y seductora, que no permite distinguir entre un principio y un final, entre los límites de las cosas del mundo, o entre el contenido y el continente, genera al mismo tiempo una sensación perturbadora y atrayente, como esos abismos de dinamismo vertiginoso que nos subyugan. Una luz que podría enceguecer más que constituirse en cifra de aquello con lo que normalmente asociamos a la luz: la verdad o el conocimiento.

Hoeksema, con gran intuición y lucidez toca el centro cuando escribe a propósito de Sólo esta lur: "Los poemas de Isabel Fraire no son estrictamente sobre el método poético. No tienen que ver tanto con la creación dentro del pensamiento como con el proceso del pensamiento en el acto de la creación" (16). Fraire ve en los efectos de la luz en el mundo un símbolo paralelo a lo que sucede cuando el poeta crea. Así como la luz total ciega o absorbe y difumina los 
contornos de las cosas, y se precisa de una luz combinada con cierta dosis de sombra para perfilar y dar cuerpo a los objetos y seres del mundo, así en el poeta el pensamiento, la conciencia creadora va perfilando la palabra poética. Señala Hoeksema: "Fraire es a menudo el poeta que se sorprende en el acto de autopercepción. Sus poemas son un espejo del proceso de creación en el pensamiento ante la imagen de la propia conciencia del poeta, a saber: la luz.” (16)

\section{La realidad amenazante}

En su primer poemario, Fraire pensaba la luz y el problema ya planteado por Paul Valéry con una buena dosis de racionalismo, sobre cómo se desplegaba la actividad del pensamiento en los instantes de la creación. Qué papel jugaban los sentidos para conocer al mundo y cómo se expresaba esa palabra precisa que constituía el reflejo de la conciencia del autor. Ese poemario lo cierra una pequeña colección de poemas titulada Encuentros casuales, largamente meditadas rendiciones, que no caben en aquel otro y en los que el tono ha cambiado y también el tema. Un primer poema de escasos tres versos parece una advertencia del desajuste en el mundo:
Anda el amor suelto por las calles
disperso en las miradas
sin encontrar un sitio (Kaleidoscopio 83)

El sentimiento más poderoso, el amor, que siguiendo a Hesíodo en su Teogonía es el origen del cosmos, el que libera o desata las fuerzas, no logra su cometido. No acierta en ningún blanco, es errático. El desencuentro es quien tiene el cetro. Sí hay poemas todavía donde la luz es central, sin embargo comienza a introducirse la muerte. Dice en uno de ellos:

Yo creía que la muerte era una forma más de ser y no la otra cara de las piedras presentes ... se abrió la tierra y se tragó los pájaros del alba que contenían tus manos 
... y yo, vigilante impávida, presenciaba

la desintegración del universo. (94)

En otro: "Éste es el tiempo en que la muerte / nos corteja y coqueteamos" (95). En uno más: "Todo lo conocido se deshace / todo lo que tocamos se evapora" (96); o aquel que sencillamente titula "Poema", dedicado a José Emilio Pacheco, y en el cual se pregunta "qué mundo es éste" (101) con desaliento y pesadumbre de ver nacer el día envuelto en las noticias que suponemos tremendas. Pero hay otro donde se instala especialmente el poder de la destrucción, de algo oscuro que nos come a nosotros y al mundo:

Siento alrededor de mí una lenta corrupción que todo invade y que no es ese viejo juego inevitable de la vida con la muerte

hay algo más aquí

una herida gangrenada que se abre

en las miradas

en el árbol mutilado

no acabaría nunca de contar las señales

de este lento cambio que avanza

atacando las raíces de los ojos

invadiendo las venas de un mundo

$\cdots$

cuando ya

Que no acaba aún de nacer

una lenta invasión de basura carcome hasta los árboles una invasora desesperanza se apodera de los niños

un oleaje duro atropella los ojos (103)

Esta realidad arremete cotidianamente contra cualquier concepción de orden y armonía, las barre como bulldozer. La percepción de Fraire sobre el mundo ha virado, parece que la luz finalmente ha revelado los objetos con los cuales el ser humano ha revestido al planeta y son deformaciones. Hemos creado monstruos que van contra la naturaleza, pisando y destruyendo. El tigre que aparecerá 
en una línea posterior bellísima en su poder devastador comienza a acechar, aunque todavía no se haya nombrado.

El tigre ha sido asociado, por algunos poetas, con el paso del tiempo demoledor que acecha y tritura, y también con una forma desesperada de la soledad como en el poemario El tigre en la casa, de Eduardo Lizalde. William Blake lo dimensiona como la destrucción y la fuerza. Para Jorge Luis Borges es cifra de la imposibilidad, lo que no se puede alcanzar con la palabra pero que se empeña en ese anhelo. Nietzsche simboliza en la imagen "del lomo de un tigre" (228), en su ensayo Sobre verdad y mentira en sentido extramoral, aquello que la conciencia humana ha querido desterrar o no ver en su propia naturaleza: “. . . crueldad, codicia e instintos insaciables y homicidas! ¿De dónde iba a surgir, en semejantes condiciones, el impulso hacia la verdad?" (228). El ser humano tiene una "conciencia soberbia y engañosa” (228) sentencia Nietzsche. Considero que varia de la producción poética de Fraire camina muy afín con esa línea de pensamiento nietzscheana, sobre todo a partir de Poemas en el regazo de la muerte (1978).

La poeta regiomontana usa la expresión "la realidad es un tigre" (Kaleidoscopio 137) porque todo lo terrible que como humanidad producimos en el mundo, pero también todo lo hermoso que está ahí, afuera de la persona, espera o acecha como este poderoso y terrible animal selvático, y solamente hay que animarse a reconocerlo y, a veces, dejarlo entrar. En la poesía de Fraire encontramos lo que prefigura esa realidad amenazante, aunque también en otros momentos alude a una transparencia pasmosa, lo vivificante; una dualidad temible que siempre es el ser humano; un ángel terrible: bello y homicida, como decía Nietzsche.

La relación que se nota en la poesía de Fraire, entre la voz poética y las ciudades en las que vivió: Londres, Ciudad de México, París, Nueva York, son reflejo de la tensión con la cual la poeta se sentía en el mundo. Aunque no se puede afirmar que sea una conciencia intranquila y desajustada como la que experimenta el responsable o culpable de algún desastre; es más bien una especie de testigo que se obliga a sí misma a dar cuenta de lo que su atención capta. La mayor parte de las veces, a partir de su segundo libro, la poeta nos 
sitúa frente a un mundo inhóspito, hostil. Las imágenes que se instalan en sus versos muestran un ser humano indolente, causante de un entorno sumamente complicado. A la vuelta de los años se nos ha revelado como pitonisa. Nos ha tocado ahora ser parte acusada de esta enorme crisis humanitaria global de la cual participamos y en la cual vivimos. Y eso Fraire lo hace patente en varios de sus poemas y textos periodísticos.

El poema "En una estación del metro una niña negra" describe una viñeta de lo que seguramente acontece con frecuencia en ese medio de transporte masivo, en la metrópoli de Nueva York: una madre bastante drogada no puede siquiera encontrar el modo de atravesar los torniquetes de paso a los andenes, mientras la hija, llorando, le comunica a alguien más por el teléfono: "me quiero ir / me quiero ir a casa" (210). La escena retratada en los versos es de una crudeza brutal. Fraire, como es su estilo, no echa mano de recursos retóricos. Nos confronta con esa realidad dolorosa sin casi emotividad, con muy escasas palabras; y por eso mismo, el contraste resulta tremendo. El lector termina por sentir físicamente la impotencia, el miedo y el peso soportado por la niña que literalmente "no puede con el paquete" (210) de lo que le significa la madre. Los papeles están completamente invertidos: la figura que debía ser protectora y guía deambula perdida en los paraísos de la droga "alta elegante hierática como diosa africana / o modelo de Vogue / flota impotente por encima de la realidad" (210), mientras la pequeña "chilla por teléfono" (210): "mírala ... mírala cómo está / y de esta estación / no sé irme a mi casa” (210). Esta viñeta condensa el otro lado de Nueva York, el que se queda en la sombra, el que no pasan en las películas ni en la publicidad por no destruir el sueño inventado de la gran metrópoli. Fraire, con ese movimiento suyo tan magistral de las palabras revela la engañifa y, entonces, la falsación de la realidad queda al descubierto.

El detalle cotidiano es muy importante para la poeta; pero no como el miniaturista que coloca todo el recorte de mundo seleccionado en la pequeña superficie que ha destinado para ello, sino porque cada elemento de la realidad le parece sobresaliente. La jerarquización en su poesía no corresponde a ninguna que la sociedad 
haya establecido comúnmente. Por tanto, en su escritura no hay temas más poéticos que otros, o más notables que otros. Eso, el distingo, lo que marca la diferencia, queda como territorio exclusivo de la afinación de la mirada. Quién mira y cómo mira esto o aquello.

La visión del jardín como un producto de la racionalidad humana es un ejemplo de las imágenes tan certeras que compone, y lo es también de su cosmovisión: ¿qué hace el hombre con el mundo? ¿cómo lo habita? Sólo lo habita modificándolo, pero los resultados de esta alteración de la naturaleza, muchas veces han conducido al desastre. El jardín es la versión domesticada de la fuerza silvestre del bosque o de la selva, espacios rituales y templos desde los primeros tiempos. Al volverlos ordenados, el ser humano aculturado piensa que tiene todo bajo control, que organiza el mundo. Así como traza las calles de las ciudades, coloca adoquines, monumentos, edificios bancarios y departamentos, acota la cantidad de espacio verde que debe ir en tal o cual sitio. Pequeños pulmones de la ciudad, les llaman ahora. Cuando se diseñó uno de los primeros, Versalles, en realidad se quería mostrar la magnificencia del rey Luis XIV, cómo su poder se extendía hacia la exuberancia de la naturaleza. Tiene algo de monstruoso ver ese enorme jardín, 800 hectáreas (8 millones de metros cuadrados) con sus extravagantes formas geométricas, setos rectangulares, el pasto en espirales y círculos, cortado a cuchilla simétricamente. En Fraire, los jardines se resemantizan también:

Les ofrezco una nueva definición del hombre el hombre es un animal que hace jardines tan específicamente humano es el jardín como la pirámide el acueducto el palacio o el edificio de departamentos (130)

El anterior pertenece a un pequeño grupo de cuatro poemas con el jardín como centro, contenidos en el libro Poemas en el regazo de la muerte. En el siguiente, Fraire nos convence de que "el jardín tiene muros / o finge no tenerlos" (131), es decir, que la libertad que apa- 
rentemente ganamos en ese recorte de ciudad al cual denominamos jardín porque nos han convencido de ser ése el sitio donde se solaza el cuerpo y el espíritu, de cualquier manera es una especie de encierro circundado por muros. Ahora bien, el ser humano tiene dos vías posibles frente a esta circunstancia: acepta la reclusión y la convierte en un refugio florido, en un sitio de "defensa" (131); o bien quien no reconoce esos muros "pretende que su jardín se extiende / más allá de sus límites... que equivale al universo / que todos pueden entrar en su jardín” (131). Esta última es una visión optimista de la vida. Se ha reconvertido la sociedad carcelaria, condensada por la poeta en aquello que paradójicamente simbolizan los espacios verdes de las grandes urbes seccionadas a su vez en conglomerados menores llamados fraccionamientos, porciones de gente aglutinada en grupos de casas o, peor aún, de departamentos para aprovechar de mejor manera el espacio.

Una no deja de pensar en la sed tan implacable que la imagen de la ciudad moderna suscitaba en ese puñado de escritores liderados por Baudelaire, un ansia por sus excesos y desvaríos, sus paraísos e infiernos. Ese anhelo metaforizado en la gran urbe, promesa de experiencias verdaderas - como si la experiencia en sí no fuera otra cosa que verdad, antes que nada-, señuelo y diosa para tantas generaciones posteriores. Pero este mito no funcionó para Fraire. Descubrió sus chapuzas muy rápido, como buena observadora del ritmo interior y exterior de las cosas, porque como afirma en otro poema de este grupo de los jardines: "el Edén es una pasajera concreta realidad" (133), un microcosmos que uno mismo ha ido permitiéndose cuando hay las posibilidades de salud mental y física, o económicas, sociales o políticas. En otro poema de este mismo libro desmonta, capa por capa, lo que significa vivir en uno de los grandes inventos del siglo XX diseñados para acomodar a la muchedumbre: los "Complejos habitacionales" (149), cubos cada vez más pequeños y asfixiantes en los cuales nos hemos acostumbrado a pasar los días de nuestra existencia, simulando ambientes de privacidad, pero donde:

ocasionalmente

se oye a través de las paredes

una discusión agria violenta 
cargada de resentimiento

de una vida estropeada

o la música de fondo

melodramática y jadeante

de la televisión (151)

Aquellos conjuntos de departamentos que rasgan la vista y la conciencia del lector, casi con la brutalidad de la conocida imagen de Luis Buñuel en El perro andaluz, una brutalidad igual pero con un recurso opuesto, son la viva imagen del intento por imponer un orden al caos del crecimiento poblacional y la desigualdad de condiciones. Todos corremos en pos de la ilusión, también inventada, de tener un "piso"; si es en una urbe prestigiada, qué mejor. En una de sus crónicas-ensayos Fraire descubre los despostillados de Nueva York, con una minuciosidad y detalle dignos del mejor sociólogo: ${ }^{2}$

Otros turistas acuden a las calles en donde florecen, desbocados, los centros de la industria del sexo en todas sus variantes. Allí ceden impunemente a los reclamos de los placeres de todo tipo, orgiásticos o solitarios, en vivo o en video y para todos los bolsillos. La octava avenida, por ejemplo, junto a la zona de los teatros, o bien ciertas calles de Greenwich Village, hoy convertidas en zona rosa mezclada de ghetto homosexual, en donde el transvestismo, la prostitución callejera masculina y femenina y la drogadicción saltan a la vista de cualquiera y a todas horas, pero sobre todo en verano. $\mathrm{O}$ el barrio chino, en donde las mercancías electrónicas, la ropa y los comestibles frescos o enlatados de todo tipo se consiguen

${ }^{2}$ Fraire tradujo La guerra secreta en México, investigación de Friedrich Katz sobre la historia social y política del México moderno, lo mismo que la Introducción a la sociología histórica marxista de Ross Gandy y Una muerte en la familia Sánchez, de la saga de Óscar Lewis. Todos estos materiales se relacionan entre sí con disciplinas que entreveran la historia, la sociología y la antropología. No podría ser una casualidad. Estos eran enfoques que también interesaban a Fraire. 
a la cuarta parte de su precio normal y los burdeles cárcel y las fábricas cárcel proliferan en una ilegalidad tolerada.

De hecho la corrupción de la policía neoyorquina es un escándalo nada secreto que aflora en los periódicos y en los tribunales periódicamente, y la cantidad de reglas que se rompen cotidianamente con la anuencia tácita de las autoridades, sobre todo en los barrios más populosos y menos afortunados, va destruyendo el tejido mismo de la sociedad. ("El Nueva York")

Fraire fue una viajera, conoció muy bien distintas culturas y formas de vida. El hecho de que su esposo fuera diplomático les facilitó movilidad y acceso por distintos países de Europa, Estados Unidos, Latinoamérica y de vuelta a México "irse para volver" (241) a darse de frente con la ciudad donde masacraron a tantos estudiantes en Tlatelolco y que ella consigna en el poema "2 de octubre en un departamento del edificio Chihuahua”. José Homero Hernández Alvarado reflexiona que Fraire a partir de Poemas en el regazo de la muerte, continúa con la poética objetivista, con ese "esmero por mostrar la cosa en vez de describirla", pero con "un desplazamiento hacia los acontecimientos cotidianos, representados . . como viñetas de la alienación contemporánea en las ciudades metropolitanas —París, Nueva York, Londres" (“Entre la palabra” sp). En uno de los últimos poemas que dejó inéditos pero que se compilaron en la edición del Fondo de Cultura Económica, Kaleidoscopio insomne. Poesía reuni$d a$, nos interpela:

$$
\begin{aligned}
& \text { ¿íganme en serio } \\
& \text { vale la pena }
\end{aligned}
$$

Me pregunto, ¿quién podría tener una respuesta rotunda, categórica? Queremos tener esperanza en que podemos hacer de este mundo un lugar más habitable, pero todos los días nos desayunamos con noticias que compiten entre sí para ganarse el galardón de ser las más horrendas. Cebamos a un tigre, a una realidad, cada vez más feroz. 
En conclusión, Isabel Fraire es una poeta reconocida desde su primer libro como una escritora de primer orden; sin embargo, ha sido muy poco atendida por la crítica especializada, pese a su participación activa en el grupo de la Casa del Lago o Generación de Medio Siglo y en la prestigiada Revista Mexicana de Literatura. Como ha señalado de forma amorosa y también picante Dionicio Morales en su "Carta de relación a Isabel Fraire", como homenaje a la poeta en ocasión de su 75 aniversario: "Pertenecías ... hay que decirlo, al famoso grupo de la mafia cultural de aquellos años que controlaba todos los espacios culturales de México, es decir los más importantes" (15). Morales, es justo decirlo, elogia en esta carta a su amiga Fraire. No le reclama absolutamente nada. Pero sí cree que hay algunos en este "grupo" que manejaban los hilos culturales del centro del país, que es un poco decir también del país entero. Este no era el caso de Fraire. Su protagonismo en la historia de la literatura mexicana es casi nulo. Su presencia como figura literaria es más bien tenue, sin mucho ruido; aunque sea una de las cuatro mujeres incluida en la célebre selección de Paz, Chumacero, Aridjis y Pacheco, Poesía en movimiento. Discreta como figura y muy contundente en su poesía. Nos hizo ver la claridad de la luz como metadiscurso para hablar conceptualmente de la poesía, y en sus libros posteriores asentó su palabra en la realidad, sin olvidar la perfección de su forma directa y aparentemente radicada en la sencillez. Algunos de sus versos desde Poemas en el regazo de la muerte nos interpelarán desde las atrocidades que hemos cometido como especie humana contra la naturaleza, contra las demás especies y contra el ser humano mismo. Hemos convertido al mundo en un lugar cada vez más inhóspito, nuestra huella se distinguirá por las masacres, por la arrogancia del concreto que arrincona selvas y boscaje, por la degradación y la inhumanidad. El antiguo tigre que metaforizaba la fuerza poética representa ahora nuestro lado más oscuro: el de la criminalidad y la ignominia.

\section{Bibliografía}

Flores, Miguel Ángel. "Escritores y poetas mexicanos: Isabel Fraire". Archivo de voz e imagen de escritores y poetas mexicanos, 2012, 
Universidad Autónoma Metropolitana, www.youtube.com/ watch?v=6dYFRKe6bk\&ab_channel=UAMVIDEOS

Fraire, Isabel. Kaleidoscopio insomne. Fondo de Cultura Económica, 2004.

. "El Nueva York de los turistas". Isabel Fraire, www.isabelfraire.com/index.php/homepage-6/el-nueva-york-de-los-turistas . Seis poetas de lengua inglesa. Pound, Eliot, Cummings, Stevens, Williams, Auden. SepSetentas, 1976.

. "Sin título". Diálogos: Artes, Letras, Ciencias humanas, volumen 7, no. 2, marzo-abril 1971, p. 24.

. "Son chones y asi son". Isabel Fraire, www.isabelfraire.com/ index.php/homepage-6/son-chones-y-asi-son

."Tres poetas mexicanos". El corno emplumado, no. 27, 1968, pp. 36-45.

García Ponce, Juan. "Nota introductoria". Isabel Fraire. Material de lectura, no. 82, 2010, pp. 5-6.

Hernández Alvarado, José Homero. "Entre la palabra y el mundo". Isabel Fraire, www.isabelfraire.com/index.php/homepage-7/entre-la-palabra-y-el-mundo-jose-homero

Hoeksema, Thomas. "Isabel Fraire: El ojo arrobado". Traducción de M. A. Flores., Diálogos: Artes, Letras, Ciencias humanas, vol. 13, no. 6, 1977, pp. 14-17.

Lumbreras, Ernesto. "La fragilidad habitable de Isabel Fraire". Milenio, 11 abril 2015, www.milenio.com/cultura/la-fragilidad-habitable-de-isabel-fraire

Morales, Dionicio. "Carta de relación a Isabel Fraire". Casa del tiempo, no. 33-34, 2010, www.uam.mx/difusion/casadeltiempo/33_34_ iv_jul_ago_2010/casa_del_tiempo_eIV_num33_34_14_17.pdf

Nietzsche, Friedrich. Verdad y mentira en sentido extramoral. Traducción de Enrique López Castellón, Universidad Autónoma de Madrid, 2001.

Tiempo en la casa. Casa del tiempo, no. 22, 2015, www.uam.mx/difusion/casadeltiempo/22_nov_2015/TiempoenlacasaNo22_ nov2015.pdf 